\title{
A interferência da vulnerabilidade social sobre as oportunidades educacionais nos territórios urbanos
}

\author{
The interference of social vulnerability on educational opportunities in urban \\ territories
}

\section{La interferencia de la vulnerabilidad social sobre las oportunidades educativas en los territorios urbanos}

\author{
Silvana Menegoto Nogueira Di Giusto ${ }^{2}$ \\ Vanda Mendes Ribeiro ${ }^{3}$
}

\begin{abstract}
Resumo: Este artigo advém de pesquisa que visou identificar na literatura fatores de contextos de vulnerabilidade social, que interferem na escola e podem influenciar as oportunidades educacionais nessas localidades. Para tanto, fez-se busca no Scielo, em 2017, sobre o tema. A análise do referencial denotou que há um conjunto de elementos externos e internos à instituição escolar, advindos da vulnerabilidade do território, que influenciam suas atividades administrativas e pedagógicas, como: maior carência de instrumentos promotores de bem-estar social na região; homogeneidade do corpo discente; seleção de alunos e professores; rotatividade de profissionais; formação profissional insuficiente; representação negativa dos alunos; simplificação de conteúdos e menor tempo dedicado às práticas educacionais. Conclui-se que esses elementos interferem e dificultam o desenvolvimento das funções da escola enquanto promotora de conhecimentos e acabam criando ou reforçando desigualdades educacionais.
\end{abstract}

Palavras-chave: Vulnerabilidade social no território. Desigualdades educacionais. Oportunidades educacionais.

Abstract: This article comes from research that aimed to identify in the literature factors of contexts of social vulnerability that interfere in the school and can influence the educational opportunities in those localities. For that, a search was made at Scielo, in 2017, on the subject. The analysis of the referential denoted that there are a set of external and internal elements to the school institution, arising from the vulnerability of the territory, which influence its administrative and pedagogical activities, such as: greater lack of instruments promoting social welfare in the region; homogeneity of the student body; selection of students and teachers; turnover of professionals; insufficient vocational training; negative representation of students; simplification of content and less time dedicated to educational practices. It is concluded that these elements interfere and hinder the development of the functions of the school as a promoter of knowledge and end up creating or reinforcing educational inequalities.

Keywords: Territory social vulnerability. Educational inequalities. Educational opportunities.

Resumen: Este artículo proviene de investigación que apunta a identificar en la literatura factores de contextos de vulnerabilidad social, que interfieren en la escuela y pueden influenciar las oportunidades educativas en esas localidades. Para ello, se hizo una búsqueda en el Scielo, en 2017, sobre el tema. El análisis del referencial denotó que hay un conjunto de elementos externos e internos a la institución escolar, provenientes de la vulnerabilidad del territorio, que influencian sus actividades administrativas y pedagógicas, como: mayor carencia de instrumentos promotores de bienestar social en la región; homogeneidad del alumnado; selección de alumnos y profesores; rotación de profesionales; formación profesional insuficiente; representación negativa de los alumnos; simplificación de contenidos y menor tiempo dedicado a las prácticas educativas. Se concluye que estos elementos interfieren y dificultan el desarrollo de las funciones de la escuela como promotora de conocimientos y acaban creando o reforzando desigualdades educativas.

\footnotetext{
${ }^{1}$ Submetido em: 22 out. 2018 - Aceito em: 19 mar. 2019 - Publicado em: 20 dez. 2019

${ }^{2}$ Universidade Cidade de São Paulo (UNICID) - E-mail: silgiusto@uol.com.br

${ }^{3}$ Universidade Cidade de São Paulo (UNICID) - E-mail: vandaribeiro2@ gmail.com
} 
Palabras clave: Vulnerabilidad social en el territorio. Desigualdades educativas. Oportunidades educativas.

\section{Introdução}

Este artigo é proveniente de pesquisa que visou identificar na literatura fatores de contextos de vulnerabilidade social, especialmente em grandes centros urbanos, que interferem nas atividades escolares e que podem exercer influência sobre as oportunidades educacionais de crianças e jovens que estudam nessas localidades. $\mathrm{O}$ referencial utilizado baseou-se em busca na base Scielo, realizada em 2017, com as palavras-chave "Desigualdades escolares", "Oportunidades educacionais" e "Vulnerabilidade social". Outras referências advindas de disciplinas cursadas no Programa de Pós-Graduação da Universidade Cidade de São Paulo (Unicid) foram também utilizadas ${ }^{i}$.

No final dos anos 1960, Coleman (2008) e Bourdieu e Passeron (1970) marcaram a discussão sobre educação escolar ao afirmarem que a escola reproduzia as desigualdades sociais, expressando essa reprodução nas desigualdades educacionais, na trajetória escolar e na inserção social dos indivíduos. Seus estudos revelaram que a maior parte dos alunos com menor nível socioeconômico apresentava vida escolar mais conturbada, com reprovações e evasões, e suas escolhas profissionais não diferiam sobremaneira, em termos de inserção social, daquelas de seus pais. Especialistas afirmam que a "descoberta" da correlação entre desigualdade escolar e nível socioeconômico ou background familiar gerou uma nova percepção sobre o que é a justiça na escola. Dubet (2009) reitera que essa descoberta se deu devido à massificação escolar. Para Meuret (1999), refletir a respeito da distribuição das competências que os indivíduos aprendem na escola passou a ser uma questão de justiça desde então, uma vez que a desigualdade produzida pelas diferenças de competências adquiridas na escola é consequência e tem consequências sobre as relações sociais.

Fazendo uso da discussão sobre justiça e escola nas redes de ensino brasileiras, Ribeiro (2014) salienta que competências e aprendizagens não adquiridas na escola de forma igualitária comprometem a aquisição de outros bens sociais valorizados, como posições vantajosas na sociedade ou no mercado de trabalho. Assim, jovens egressos de instituições que não oferecem preparo cultural satisfatório, tendem a apresentar trajetórias de vida não tão favoráveis, ocupando postos de trabalho menos reconhecidos ou com salários menores, reproduzindo e perpetuando os processos de desigualdades.

Se a correlação entre desigualdade escolar e nível socioeconômico foi percebida nos anos 1960, investigações que tratam da interface entre vulnerabilidade social nos territórios ou desigualdades socioespaciais e desigualdade escolar são mais recentes. Segundo Ribeiro, Mello e Batista (2015), no Brasil, esses estudos têm início a partir dos anos 2000, como em Ribeiro e Koslinski (2010), Érnica e Batista (2012), Koslinski, Alves e Lange (2013), que detectaram pior desempenho entre alunos de escolas inseridas em territórios de maior vulnerabilidade social.

O conceito de vulnerabilidade social que alicerçou as análises da investigação baseouse em Kaztman (2000), Ribeiro (2010) e Ben Ayed (2012). Por meio da análise do referencial 
teórico, denota-se que há um conjunto de elementos externos e internos à instituição escolar, advindos da vulnerabilidade no território, que exercem influência sobre a escola interferindo em suas atividades e rotinas tanto administrativas quanto pedagógicas. Pode-se destacar: maior carência de instrumentos promotores de bem-estar social no território; homogeneidade do corpo discente; possibilidade de seleção de alunos e professores; maior rotatividade de profissionais; formação profissional insuficiente; representação negativa dos alunos; simplificação de conteúdos e menor tempo dedicado às práticas educacionais.

São elementos que se somam e se sobrepõem em influências múltiplas e mútuas que podem dificultar a construção de trajetórias escolares bem-sucedidas. Com isso, criam-se recursos deficitários para o aproveitamento de oportunidades e ampliam-se também os estigmas negativos, alimentando crenças sobre os alunos como a incapacidade de aprender, falta de interesse de suas famílias ou a existência de dificuldades ou deficiências inerentes ao aluno, o que, em uma sociedade competitiva, significa praticamente condenar crianças e jovens a permanecerem na pobreza.

Esse artigo visa evidenciar esses elementos, explicitando os achados de um conjunto de pesquisas realizadas recentemente no Brasil, a respeito de suas influências sobre as oportunidades educacionais, nos contextos de vulnerabilidade social. Para tanto, foi organizado de forma a apresentar inicialmente um panorama geral da discussão sobre vulnerabilidade social nos grandes centros urbanos, suas causas e características principais. Em seguida, trata-se da relação entre esse contexto e as oportunidades educacionais. Por fim, são feitas as considerações finais.

\section{A Vulnerabilidade social nos territórios dos grandes centros urbanos}

Ribeiro (2010) ressalta que, com o rápido e intenso crescimento das populações, além da abertura para o mercado internacional, não só no Brasil, mas em toda a América Latina, as periferias dos grandes centros urbanos foram ocupadas, primordialmente, por indivíduos e famílias com nível econômico mais baixo, usualmente excluídos das regiões mais ricas e abastecidas dos distritos. Ben Ayed (2012) complementa que o distanciamento físico de populações pobres associado à dificuldade do poder público em consolidar a universalização de direitos, com destaque inclusive para o avanço da privatização de serviços como educação e saúde, leva a uma verdadeira segregação espacial e a um isolamento social nos grandes centros urbanos.

Segundo vários pesquisadores, como Kaztman (2000), Cunha et al. (2006), Ribeiro (2010), Stoco e Almeida (2011), populações segregadas nos grandes centros urbanos apresentam dificuldades para possuir ou usufruir de ativos materiais e imateriais que lhes permitam lidar com a situação de pobreza, além disso, o acesso às oportunidades que promovem melhoria do bem-estar são restritas. Para Ribeiro (2010), enquanto a pobreza é vista como algo estático, como insuficiência de renda, a vulnerabilidade é dinâmica, podendo incorporar diferentes combinações de elementos da vida dos indivíduos e, ainda, estar associada de alguma forma a um território. 
De acordo com Seddon (2014), as pessoas em si não são necessariamente vulneráveis, mas sua vivência em condições desfavoráveis pode gerar ou agravar a vulnerabilidade pessoal ou da família. O território, por sua vez, pode concentrar pessoas em situação de vulnerabilidade, tornando, assim, um círculo vicioso que se retroalimenta. Para Kaztman (2000), há uma combinação de fatores presentes em algumas localidades que caracterizam a vulnerabilidade social de um indivíduo ou grupo, como: frágeis laços com o mercado de trabalho - com menor vínculo de estabilidade e exclusão a postos de melhor qualidade; isolamento sociocultural e político; homogeneidade social dos bairros; baixa escolaridade de seus moradores; baixo acesso à serviços públicos e privados, bem como serviços precários, dentre outros fatores.

Considerando tais apontamentos, especialistas têm salientado que a vulnerabilidade social no território não pode ser captada por uma variável somente, como a de renda, por exemplo. Para a caracterização de situações de vulnerabilidade social devem-se considerar, além dos indicadores de renda familiar, outros referentes à escolaridade, saúde, condições de inserção no mercado de trabalho, acesso aos serviços prestados pelo Estado e oportunidades de mobilidade social.

A fim de identificar e buscar melhores formas de enfrentamento dessas situações, assim como de mensurar e acompanhar as intervenções governamentais, diversos estados desenvolveram metodologias para caracterizar as populações que enfrentam problemas de sobreposição de desigualdades, em geral nas periferias das grandes cidades. No estado de São Paulo, especificamente, a Fundação Sistema Estadual de Análise de Dados (SEADE) desenvolveu o Índice Paulista de Vulnerabilidade Social (IPVS), calculado pela combinação da dimensão socioeconômica e do ciclo de vida das famílias. Leva em conta a renda média do chefe da família, sua idade e seus anos de estudo formal, além da questão territorial, que age como causa e consequência para as questões de desigualdades. Combinadas, essas dimensões geram sete grupos classificatórios distintos que vão desde baixíssima até muito alta vulnerabilidade social (ÉRNICA; BATISTA, 2012).

Determina-se que, quanto menores esses índices, menor é a qualidade de vida e maior a vulnerabilidade social. As pesquisas têm indicado que nesses contextos há maior dificuldade ao acesso ou aproveitamento de oportunidades de toda sorte, inclusive ao que se refere à Educação. Assim, indivíduos ou grupos sociais nestas condições vivem em uma situação frágil e precária, distante ou mesmo excluídos dos benefícios e das condições de dignidade e direitos básicos de cidadania (SEADE, 2010; COSTA; MARGUTI, 2015).

\section{A vulnerabilidade social e as oportunidades educacionais}

A escolarização é considerada, na literatura especializada, um dos recursos que mais influenciam a inserção das pessoas nas formas de obtenção de bens e serviços, e um dos benefícios sociais que mais modificações trazem às famílias, inclusive quanto à mobilidade social. Autores como Heyneman e White (1986) e Carnoy (1986) reiteram que essas afirmações são, sobretudo, mais verdadeiras quando se trata dos países em desenvolvimento. 
A falta ou o funcionamento deficitário das escolas, entendidas como agentes de transmissão de capital cultural, afeta significativamente crianças e jovens em idade escolar, trazendo impactos presentes e futuros a esses indivíduos.

Ribeiro e Koslinski (2010) referem que o contexto de vulnerabilidade social é um dos fatores que pode impactar negativamente as oportunidades educacionais das populações segregadas nos espaços urbanos. Trata especificamente da chamada influência da vizinhança sobre o indivíduo ou Efeito Vizinhança, ou seja, o impacto do local de residência e das características sociais de sua população sobre as condições de vida e de mobilidade social de seus moradores. Esse efeito, para os autores, ocorre por três distintos mecanismos.

O primeiro seria a desorganização social presente nesses contextos, inclusive com traços de violência, o que gera tendência à repetição de comportamentos de risco por parte de seus moradores. O segundo seria o processo de socialização influenciado pelo entorno, com normas e padrões de comportamento sendo aprendidos de acordo com a interação frequente. Muitas vezes, nessas localidades segregadas, há desconexão de interações com os padrões de bem-estar da sociedade, em especial, com modelos de adultos bem-sucedidos via escolarização. Por fim, o terceiro seria o fator institucional, a qualidade de bens e serviços oferecidos no entorno social afetaria o indivíduo. Normalmente, os locais mais vulneráveis estão desprovidos ou pobremente equipados de recursos promotores de qualidade de vida, como hospitais, escolas, segurança, transporte e cultura, interferindo nas oportunidades de crescimento pessoal e coletivo.

De acordo com Érnica e Batista (2012), o impacto do Efeito Vizinhança seria especialmente significativo em regiões marcadas pela desigualdade socioeconômica e educacional, pela segregação sociocultural e/ou por contextos onde a presença do Estado de Bem-Estar não está consolidada e capaz de universalizar direitos. Especificamente, o Efeito Vizinhança sobre a Educação, refere-se ao impacto do território sobre o destino escolar de seus indivíduos. Em geral, entende-se que escolas inseridas em locais com populações muito vulneráveis socialmente tendem a apresentar dificuldades para manter satisfatoriamente suas funções primordiais de ensino. Assim, compreende-se que a produção e reprodução de desigualdades escolares estariam também associadas à estratificação social e às condições de ofertas educacionais. Érnica e Batista (2012) resumem em cinco fatores principais que podem justificar o surgimento desse efeito sobre a Educação:

1 - Carência de benefícios promotores de bens sociais na região, como por exemplo: meios de transporte, saneamento básico, estabelecimentos de ensino, postos de saúde, hospitais, segurança, ofertas culturais, entre outros. A inexistência ou a má distribuição desses elementos leva a escola, quando presente, a um cenário de isolamento e, muitas vezes, a lidar com situações adversas fora do seu preparo e sem apoio de serviços públicos, como nos casos de violência dentro ou contra a instituição.

2 - Baixa oferta de matrículas para a educação infantil. Essa situação pode afetar sobremaneira as condições de sucesso educacional dos indivíduos. Isso porque com frequência, as famílias em regiões de alta vulnerabilidade apresentam menores recursos culturais, considerando aqui a escolarização e o contato com ambientes formais de educação. Flores (2008) refere que a família é responsável por trazer estratégias educacionais que 
impulsionam o aluno na sua trajetória dentro de um sistema formal de escolarização, como a transmissão do capital cultural; o incentivo aos estudos; o estímulo ao interesse escolar, entre outros. Sendo assim, quando esses fatores estão ausentes ou enfraquecidos, o período preparatório infantil exerce importante papel, introduzindo as crianças no ambiente estudantil, proporcionando os primeiros contatos com os códigos e saberes da cultura escolar.

3 - A homogeneidade sociocultural dos alunos desses estabelecimentos, geralmente apresentando baixos recursos culturais familiares e residindo próximo da escola. Os comportamentos apresentados são bastante similares, manifestando-se por vezes de forma intensa e em proporções de difícil controle por se tratarem de quase uma unanimidade. Promove-se assim, quase um isolamento de costumes, que reproduz as diversas condições próprias do entorno, dificultando o desenvolvimento escolar e gerando estigmas negativos tanto para a instituição como para os estudantes dessas localidades.

4 - Possibilidade de escolha de estudantes e profissionais. As escolas localizadas em territórios menos vulneráveis acabam sendo disputadas por profissionais e alunos que nelas querem participar. Com isso, têm a possibilidade de realizar uma seleção automática no momento da matrícula, geralmente realizada pelos próprios agentes administrativos. A tendência é aceitar aqueles mais capacitados e interessados no processo escolar e rejeitar alunos considerados "não adequados" por não apresentarem perfil ideal, como a suspeita de indisciplina, por exemplo. Para os autores, enquanto algumas escolas conseguem "exteriorizar" alunos considerados indesejáveis, outras em locais de maior vulnerabilidade social resignam-se em receber os indivíduos rejeitados. Dessa forma, contribui, junto com o público de seu entorno, para a homogeneidade cultural dos alunos e maior desinteresse do corpo docente e administrativo.

\section{5 - Precariedade no acompanhamento do modelo institucional que orienta a}

escola. Toda instituição escolar atua no sentido de levar seus participantes em determinada direção, para tanto, necessita que o corpo discente e docente esteja preparado e engajado em suas propostas educacionais. Faz-se necessário organização e planejamento administrativo e pedagógico. Entretanto, em meio a um ambiente desfavorável, com público pobremente preparado para as rotinas escolares e com grande absenteísmo e rotatividade de profissionais surgem inúmeros obstáculos, podendo até inviabilizar a execução e continuidade de projetos educacionais.

Alves et al. (2014) complementam esse panorama com dados que indicam que, docentes concursados e mais experientes, optam, via de regra, por escolas em locais menos vulneráveis. Nesse sentido, Torres et al. (2010) confirmam em suas investigações que há maior quantidade de professores efetivos e mais experientes em regiões centrais e menos pobres da cidade. Com isso, docentes com menor experiência ou capacitação profissional acabam sendo designados para escolas em regiões mais pobres e, geralmente, com maiores dificuldades tanto pedagógicas quanto disciplinares. Foi observado também pelos autores, que em escolas de localidades mais vulneráveis, há maior número de absenteísmo e licenças. Desta forma, a grande rotatividade de funcionários, com realocação frequente dos locais de trabalho, dificulta a permanência de profissionais experientes, prejudicando a integração da equipe e a continuidade de programas e planejamentos educacionais. 
Pesquisadores têm buscado evidenciar que além do efeito da origem socioeconômica da família e da escola, a vizinhança ou o bairro como instâncias externas também são capazes de influenciar o meio escolar de diferentes formas e gerar desigualdade de oportunidades educacionais. Surgem então estudos que buscam compreender melhor fatores institucionais influenciando a Educação, como a atuação dos professores, suas representações e suas práticas quando em contextos de vulnerabilidade social.

Para Érnica e Batista (2012), a vulnerabilidade do território afeta sobremaneira a escola. Suas investigações em regiões vulneráveis da cidade de São Paulo detectaram que, crianças oriundas de famílias com baixo capital cultural quando estudam em escolas de regiões menos vulneráveis, têm melhor rendimento escolar. E o contrário também se mostrou verdadeiro, alunos em escolas com entorno mais vulneráveis, tendem a apresentar pior desempenho escolar. Assim, aparentemente, a precariedade da organização social do território é capaz de limitar a eficácia da escola e seu papel de democratização do acesso às oportunidades educacionais.

Ribeiro e Koslinski (2010) também encontraram resultados semelhantes em suas investigações no município do Rio de Janeiro. Entretanto a cidade apresenta algumas especificidades próprias, com bairros de classe média e alta próximos às comunidades pobres (favelas), combinando um panorama de proximidade física, mas de distância social. Identificaram que o desempenho das crianças em escolas muito próximas às comunidades pobres, mesmo quando inseridas em bairros abastados, era pior quando comparado aos resultados de alunos de instituições mais afastadas dos locais onde a vulnerabilidade social era mais marcante.

Complementando esses dados, Koslinski, Alves e Lange (2013) em outro estudo também no Rio de Janeiro, detectaram que escolas localizadas em áreas periféricas ou em comunidades pobres, mesmo próximas a bairros abastados, apresentavam piores condições de infraestrutura escolar e maior absenteísmo e rotatividade de profissionais, o que comprometia diretamente o desempenho das escolas e de seus alunos. Além disso, identificaram também comportamentos diferenciados, ou mesmo preconceituosos, de alguns profissionais em relação aos alunos, como baixa expectativa acadêmica, descrédito quanto ao desempenho educacional e a continuidade dos estudos até o nível superior, fatores que acabam afetando a dinâmica de ensino e aprendizagem, levando a adaptações, nem sempre positivas, das práticas escolares.

Flores (2008) estudou escolas em comunidades periféricas na cidade de Santiago do Chile e afirma que, além do efeito Vizinhança sobre a Educação ainda existe outro fator que seria a forma como cada indivíduo lida com as adversidades que lhe são apresentadas, processo construído de formas diferentes de acordo com fatores individuais, familiares e experiências vividas. A autora traça uma reflexão a respeito das situações vividas por estudantes de classe mais baixa nas escolas, identificadas como estigmas negativos associados aos territórios. Refere-se ao julgamento da capacidade das crianças de acordo com seu nível sociocultural, influenciando as práticas e comportamentos, como por exemplo, considerar jovens de áreas segregadas inaptos para educação universitária. Afirma, especialmente, que quando tais comportamentos vêm de professores acabam por diminuir a 
autoestima do indivíduo, afetando seu filtro de percepção de oportunidades. Assim, a pessoa tende a pensar que seus objetivos estão distantes ou são inatingíveis, como crer ser incapaz de obter uma trajetória escolar de sucesso ou estudos mais avançados. Este fator associado aos locais onde as oportunidades já são menores pode levar ao aumento das desigualdades.

Ribeiro (2010) discute os fatores de vulnerabilidade que bloqueiam ou dificultam a aquisição desses recursos, materiais ou imateriais, que dotam o portador de uma futura herança para integração na sociedade. São fatores adquiridos e apreendidos nas relações familiares, sociais, escolares e de trabalho. Em contextos de vulnerabilidade social, esses fatores ocorrem de forma débil ou insuficiente dificultando o acesso ao capital cultural, econômico ou social.

Batista e Carvalho-Silva (2013), após estudarem um bairro segregado, em área de alta vulnerabilidade na cidade de São Paulo, observaram embates frequentes entre famílias estudadas e as escolas. As famílias sentem-se estigmatizadas, desvalorizadas e "invisíveis" para a escola, enquanto isso, os agentes escolares alegam omissão, pouco apoio e falta de colaboração com o processo educacional das crianças. Os autores perceberam que essas famílias valorizam e depositam sobre a escola grandes expectativas. Esperam que seus filhos alcancem melhor escolaridade que a sua e que possam entrar no mercado de trabalho mais facilmente. A grande expectativa sobre a escolarização também foi observada por Barbosa e Sant'Anna (2010) em pesquisa realizada na cidade do Rio de Janeiro. Evidenciaram que as famílias que mais valorizam a educação escolar são as que têm filhos com piores desempenhos, como: moradores de favelas, com empregos mais precários ou menor escolaridade. E essa valorização está atrelada à expectativa de alcance de posições sociais mais vantajosas para seus filhos por meio da escola. Essas famílias vivem em comunidades mais distantes de instituições com melhores condições de funcionamento, portanto encontram-se em condições de segregação territorial, o que dificulta ainda mais a superação, via Educação, do quadro de precariedade em que vivem. Entretanto, de acordo com as autoras, as escolas parecem ser incapazes de reconhecer esse valor atribuído à educação por parte dessas famílias vulneráveis e segregadas.

Outros estudos agregam elementos importantes, no que concerne à capacidade das instituições escolares, que podem interferir sobre as oportunidades educacionais nesses territórios, que seriam a formação dos profissionais e as adaptações de suas práticas pedagógicas.

Breches (2015), em seu estudo sobre formação continuada de educadores e suas dificuldades de atuação profissional em uma região de alta vulnerabilidade social na cidade de São Paulo, constatou a existência de professores do ciclo de alfabetização que não participam dos momentos de formação continuada. Para esses profissionais, o autor afirma, as trocas de experiências entre pares, relevante característica da formação continuada, ficam circunscritas, em muitos casos, aos momentos informais (no café, nos corredores, durante a carona etc.) e efetivadas de forma breve e concisa. Essas práticas, conclui, mostram-se insuficientes para suprir as necessidades dos professores, uma vez que expressam dificuldades diante das exigências da alfabetização e o comportamento dos alunos, fato que pode prejudicar o ensino ofertado em um contexto que exige mais atenção. 
Christovão e Santos (2010) destacam o baixo investimento pedagógico e a simplificação dos currículos, em regiões de alta vulnerabilidade social, após estudo na cidade do Rio de Janeiro. Notaram discrepâncias entre os currículos oficial e real aplicados pelos professores. Observaram que os educadores, geralmente oriundos da classe média, sentem-se distantes e desvinculados da realidade dos alunos de localidades mais vulneráveis. Este fator acaba levando a atitudes estigmatizantes, com estudantes sendo tratados como "favelados" e à simplificação dos currículos, por considerá-los não “educáveis" (CHRISTÓVÃO; SANTOS, 2010, p. 292). Referem, ainda, que as famílias mais vulneráveis, em geral, também são depreciadas e culpabilizadas pela baixa cultura escolar dos filhos, apresentando características, como: indisciplina, desinteresse pela escola e falta de incentivo aos estudos, entre outros.

Marcucci (2015) analisou práticas pedagógicas em territórios vulneráveis na cidade de São Paulo, com base em dados de observação em sala de aula, cadernos de alunos e planos de aula de professores. Identificou simplificação de currículos; redução do tempo para escolarização dos alunos, tanto quanto à quantidade de dias letivos, como ao tempo dedicado à aprendizagem; além da pouca variação de dispositivos didáticos. A autora sugere que esses fatores podem advir da defasagem da formação docente ou pelas condições de trabalho, com planejamento de aulas insuficientes. Ou ainda, devido à baixa expectativa em relação aos alunos das localidades mais vulneráveis, interferindo no modo como organizam suas aulas.

Estudiosos sobre a desigualdade escolar têm afirmado que uma forma justa de lidar com a desigualdade de oportunidades educacionais é por meio de políticas e práticas de ensino desenhadas e implementadas com base no princípio de justiça como equidade. Uma perspectiva que exige a igualdade de base, ou seja, todos os estudantes aprendem na Educação Básica o que o Estado considera e determina como necessário (CRAHAY, 2000; DUBET, 2009; RIBEIRO, 2014). Em seu estudo, Pereira-Silva (2016) denota que a vulnerabilidade social no território desafia sobremaneira a justiça como equidade na escola, pois há uma sobreposição de fatores internos e externos à escola, que dificultam e não permitem o pleno desenvolvimento das funções da instituição enquanto promotora de saberes e acabam por impor limites à distribuição justa do conhecimento na educação básica.

Ribeiro (2012; 2014) em seus estudos sobre justiça na escola, considerando o desempenho escolar, afirma que as redes de ensino de educação básica, de direito obrigatório, deveriam agir para diminuir as desigualdades educacionais, que afetam a trajetória escolar das crianças de grupos sociais discriminados ou com menos recursos sociais - o que gera reprodução das desigualdades sociais. Com base em Crahay (2000) e Dubet (2009), a autora pondera que o princípio de justiça adequado nesta etapa escolar seria a igualdade de base ou de conhecimentos adquiridos, voltados à equidade. Assim, o Estado zela para que todos alunos alcancem as competências definidas como necessárias uma vez que essa etapa é direito obrigatório e subjetivo. De acordo com Crahay (2000), as práticas escolares consideradas para o alcance da equidade seriam: definição do conteúdo de aprendizagem em cada etapa escolar; monitoramento dos processos de implementação das políticas educacionais e dos resultados; respeito ao distinto tempo de aquisição de conteúdos de cada criança e a desvinculação com o critério do mérito. 
Como vimos, diversos estudos trazem indícios de que a vulnerabilidade social presente em territórios carrega consigo características que provocam, de forma direta ou indireta, desigualdades educacionais. A escola inserida nessas regiões é influenciada por elementos externos e internos que dificultam o desenvolvimento de suas funções promotoras de saberes e transformações, podendo levar a ofertas desiguais de oportunidades educacionais aos alunos. Externamente é influenciada pela carência de equipamentos sociais promotores de bem-estar (como hospitais, meios de transporte e segurança); baixa oferta de vagas para educação infantil; estigmas negativos em relação às escolas e estudantes dessas regiões; e famílias com níveis culturais mais baixos e distantes da cultura escolar. Os elementos internos seriam a homogeneidade do corpo discente; maior rotatividade de profissionais; a possibilidade de seleção de professores e estudantes; profissionais com formações insuficientes; baixa expectativa escolar em relação aos alunos; simplificação de conteúdos e menor tempo dedicado às práticas educacionais.

O enfrentamento dessas condições poderia ser conquistado, segundo referências analisadas, por meio de políticas públicas que promovam mudanças efetivas sobre esses condicionantes, pautadas no princípio de justiça e considerando a igualdade de distribuição de conhecimentos de forma equitativa. A literatura sobre implementação de políticas públicas traz evidências de que os objetivos de uma política nem sempre são alcançados devido à fatores humanos, culturais e sociais presentes nesse processo. São elementos que se mesclam e se sobrepõem exercendo influência sobre os processos de implementação e sobre a atuação dos agentes que a executam, interferindo na concretização das diretrizes. Lipsky (2010) destaca que os agentes de implementação exercem suas funções utilizando-se de sua discricionariedade, que permite certo grau de liberdade de atuação determinado de acordo com os diferentes contextos que se apresentam, além de suas referências e concepções pessoais e profissionais. Lotta (2014) enfatiza que a atuação dos implementadores é basicamente uma atividade relacional, amplamente dependente das relações estabelecidas entre os agentes, seus pares e o público. Hill (2003) defende a necessidade de treinamentos organizados e efetivos, a fim de alinhar conhecimentos, minimizando a diversidade de interpretações e atuações decorrentes principalmente quando há comunicação deficitária ou contraditória. Ham e Hill (1993) ressaltam que investigar essa fase da política contribui para o alcance dos objetivos e mensurar regularmente o desempenho da diretriz permite ajustes com vistas à maior eficiência e eficácia do programa.

Pode-se afirmar que a vulnerabilidade social no território impacta a capacidade de atuação da instituição escolar e a possibilidade de alcance de resultados pelas políticas que buscam mudanças e melhorias na educação. Desta forma, a fim de melhorar os níveis de igualdade de oportunidades educacionais no país, em busca da equidade, é primordial que os processos de formulação das políticas educacionais e sua implementação considerem as condições de vulnerabilidade social nos territórios, com o desenvolvimento de formas de acompanhamento dos processos e dos resultados educacionais, para apoio às escolas e profissionais que atuam nessas regiões. 


\section{Considerações finais}

Esse artigo buscou, com base na literatura, identificar fatores presentes em contextos de vulnerabilidade social, especialmente em grandes centros urbanos, que interferem nas atividades escolares e que podem exercer influência sobre as oportunidades educacionais de crianças e jovens nessas localidades. $\mathrm{O}$ referencial utilizado baseou-se em pesquisa realizada na base Scielo em 2017, com as palavras-chave "Desigualdades escolares", "Oportunidades educacionais" e "Vulnerabilidade social". E também em textos advindos de disciplinas cursadas no Programa de Mestrado em Educação da Unicid.

De acordo com a literatura aqui tratada, a vulnerabilidade social traz diversos elementos, externos e internos à instituição escolar, que interferem em suas atividades, tanto administrativas como pedagógicas. Pode-se destacar: maior carência de instrumentos promotores de bem-estar social na região; homogeneidade do corpo discente; possibilidade de seleção de alunos e professores; maior rotatividade de profissionais; formação profissional insuficiente; representação negativa dos alunos; simplificação de conteúdos e menor tempo dedicado às práticas educacionais. Esses elementos podem se somar e se sobrepor em influências múltiplas, de forma a não favorecer a igualdade de oportunidades educacionais ou o alcance de resultados equitativos, criando ou reforçando estigmas negativos e baixas expectativas em relação aos estudantes e suas famílias.

Depreende-se ainda da análise do referencial, ser relevante que as políticas educacionais considerem tais desafios no momento de sua formulação. E que os processos de implementação adotem formas de acompanhamento visando coibir o surgimento de situações que influenciam negativamente as oportunidades educacionais, como: a seleção de alunos que ocorre veladamente no momento da matrícula, privilegiando aqueles com melhor perfil escolar; a grande rotatividade de profissionais - que podem solicitar transferências constantes; ou a presença de alunos distantes da cultura escolar por não terem frequentado a educação infantil. A adoção de políticas públicas que integrem várias áreas também se coloca como urgente nesses contextos, pois a literatura aponta para a ausência ou carência de estruturas do Estado para a promoção de bem-estar social, como estabelecimentos promotores de saúde, educação, cultura e segurança. Situação que sobrecarrega a instituição escolar, estando ela, muitas vezes, em condição de isolamento, colocando-se como a única estrutura a dar suporte à região, ou mesmo tendo que lidar com eventos aos quais não está preparada, como casos externos de violência.

Desvela-se a relevância de que as políticas públicas voltadas para a Educação, assim como as práticas educacionais nesses contextos, sejam elaboradas e implementadas, considerando suas especificidades e necessidades, promovendo ações que efetivamente busquem minimizar ou eliminar dificuldades que geram prejuízos e desigualdades de oportunidades educacionais, a fim de alcançar uma distribuição de conhecimentos mais justa e equitativa para todos os estudantes. 


\section{Referências}

ALVES, Luciana et al. Remoção de professores e desigualdades em territórios vulneráveis. Cadernos Cenpec. São Paulo, v. 4, n. 2, p. 122-145, dez. 2014.

BARBOSA, Maria Ligia de Oliveira; SANT'ANNA, Maria Josefina Gabriel. As classes populares e a valorização da educação no Brasil. In: RIBEIRO, Luiz Cesar de Queiroz et al. (org.). Desigualdades Urbanas, Desigualdades Escolares. 1 ed. Rio de Janeiro: Letra Capital, 2010, p. 155-174.

BATISTA, Antônio Augusto Gomes; CARVALHO-SILVA, Hamilton Harley. Família, escola, território vulnerável. 1 ed. São Paulo: CENPEC, 2013.

BEN AYED, Choukri. As desigualdades socioespaciais de acesso aos saberes: uma perspectiva de renovação da sociologia das desigualdades escolares? Educação e Sociedade. Campinas, v. 33, n. 120, p.783-803, jul./set. 2012.

BOURDIEU, Pierre; PASSERON, Jean-Claude. A reprodução: elementos para uma teoria do sistema de ensino. Tradução de C. Perdigão Gomes da Silva. Lisboa: Ed. Vega, 1970.

BRECHES, Bryann. Formação continuada em uma escola de território vulnerável do município de São Paulo. 2015. 117 f. Dissertação (Mestrado em Educação). Universidade Cidade de São Paulo, São Paulo, SP, 2015.

CARNOY, Martin. Educação, Economia e Estado: Base e superestrutura, relações e mediações. 2 ed. São Paulo: Cortez Autores Associados, 1986.

CHRISTOVÃO, Ana Carolina; SANTOS, Mariana Milão. A escola na Favela ou a Favela na escola? In: RIBEIRO, Luiz Cesar de Queiroz et al. (org.). Desigualdades Urbanas, Desigualdades Escolares. 1 ed. Rio de Janeiro: Letra Capital, 2010, p. 277-297.

COLEMAN, James Samuel. Desempenho nas escolas públicas. In: BROOKE, Nigel; SOARES, José Francisco (org.). Pesquisa em eficácia escolar: origens e trajetórias. Belo Horizonte: Ed. UFMG, 2008. p. 26-32.

COSTA, Marco Aurélio; MARGUTI, Bárbara Oliveira (ed.). Atlas de vulnerabilidade social nos municípios brasileiros. Brasília: IPEA, 2015.

CRAHAY, Marcel. L'école peut-elle-être juste et efficace? De l'égalité des chances à l'égalité dês acquis. Belgique: De Boeck, 2000.

CUNHA, José Marcos Pinto da et al. A vulnerabilidade social no contexto metropolitano: o caso de Campinas. In: José Marcos Pinto da (org.). Novas Metrópoles Paulistas: população, vulnerabilidade e segregação. 1 ed. Campinas: Editora Unicamp, 2006. p. 143-168.

DUBET, François. Les dilemmes de la justice. In: DEROUET, Jean-Louis; DEROUETBESSON, Marie-Claude (éd.). Repenser la justice dans le domaine de l'éducation et de la formation. Lyon: Peter Lang, 2009. p. 29-46. 
ÉRNICA, Maurício; BATISTA, Antônio Augusto Gomes. A escola, a metrópole e a vizinhança vulnerável. Cadernos de Pesquisa. São Paulo, v. 42, n. 146, p. 640-666, maio/ago. 2012.

FLORES, Carolina. Segregação residencial e resultados educacionais na cidade de Santiago do Chile. In: RIBEIRO, Luiz Cesar de Queiroz; KAZTMAN, Ruben. A Cidade contra a Escola? Segregação urbana e desigualdades educacionais em grandes cidades da América. Rio de Janeiro: Letra Capital, 2008. p.145-179.

GIUSTO, Silvana Menegoto Nogueira Di. A implementação do PNAIC na rede de ensino do município de São Paulo em territórios vulneráveis. 2018.152 f. Dissertação (Mestrado em Educação) -Universidade Cidade de São Paulo, São Paulo, SP, 2018.

HAM, Christopher; HILL, Michael. The policy process in the modern capitalist state. London: Harvester Wheatsheaf, 1993.

HEYNEMAN, Stephen P.; WHITE, Daphne Siev. The quality of education and economic development. Washington, D. C.: World Bank, 1986.

HILL, Heather. Understanding Implementation: Street-Level Bureaucrats' Resources for Reform. Journal of Public Administration Research and Theory, v. 13 , n. 3, p. 265-282, 2003.

KAZTMAN, Rubén. Notas sobre la medición de la vulnerabilidad social. En: Quinto Taller regional sobre la medición de la pobreza: métodos y aplicaciones - documentos presentados. México: BID-BIRF-CEPAL, 2000. p. 275-301.

KOSLINSKI, Mariane Campelo; ALVES, Fátima; LANGE, Wolfram Johannes.

Desigualdades educacionais em contextos urbanos: um estudo da geografia de oportunidades educacionais na cidade do Rio de Janeiro. Educação \& Sociedade. Campinas, v. 34, n. 125, p. 1175-1202, out./dez. 2013.

LIPSKY, Michael. Street-Level Bureaucracy: Dilemmas of the Individual in Public Services. Original ed. 1980. Russell Sage Foundation. New York, 2010.

LOTTA, Gabriela Spanghero. Agentes de implementação: uma forma de análise de políticas públicas. Cadernos Gestão Pública e Cidadania. São Paulo, v. 19, n. 65, p. 186-206, jul./dez. 2014.

MARCUCCI, Fernanda. A educação nas grandes metrópoles: ensino de Língua Portuguesa em São Miguel Paulista. 2015. 217 f. Dissertação (Mestrado em Educação e Saúde na Infância e na Adolescência) - Universidade Federal de São Paulo, Escola de Filosofia, Letras e Ciências Humanas, Guarulhos, SP, 2015.

MEURET, Denis. La justice Du système educatif. Paris: De Boeck \& Larcier, 1999.

PEREIRA-SILVA, Célia. Vulnerabilidade social nos territórios das grandes cidades, educação e o princípio de justiça como equidade na escola. 2016. 97 f. Dissertação (Mestrado em Educação) - Departamento de Educação, Universidade Cidade de São Paulo, São Paulo, SP, 2016. 
RIBEIRO, Luiz Cesar de Queiroz. Desigualdades de oportunidades e segregação residencial: a metropolização da questão social no Brasil. Caderno CRH. Salvador, v. 23, n. 59, p. 221233, maio/ago. 2010.

RIBEIRO, Luiz Cesar de Queiroz; KOSLINSKI, Mariane Campelo. Fronteiras Urbanas da Democratização das Oportunidades Educacionais: o caso do Rio de Janeiro. In: RIBEIRO, Luiz Cesar de Queiroz et al. (org.). Desigualdades Urbanas, Desigualdades Escolares. 1 ed. Rio de Janeiro: Letra Capital, 2010, p. 121-153.

RIBEIRO, Vanda Mendes. Justiça na escola e regulação institucional em redes de ensino do estado de São Paulo. 2012. 489 f. Tese (Doutorado em Educação) - Faculdade de Educação, Universidade de São Paulo, São Paulo, SP, 2012.

RIBEIRO, Vanda Mendes. Que princípio de justiça para a Educação Básica? Cadernos de Pesquisa. v. 44, n. 154, p. 1094-1109, out./dez. 2014.

RIBEIRO, Vanda Mendes; MELLO, Hivy Damasio Araújo; BATISTA, Antônio Augusto Gomes. La Vulnerabilité sociale du territoire dans les grands centres urbains brésiliens et l'inégalité scolaire. Diversité. Montrouge, v. 3 Tri, p. 93-100, 2015.

SEADE. Fundação Sistema Estadual de Análise de Dados. Índice Paulista de Vulnerabilidade Social - IPVS. São Paulo, 2010. Disponível em: https://www.seade.gov.br/analises_estudos/indice-paulista-de-vulnerabilidade-social-ipvsversao-2010/. Acesso em: 20 out. 2018.

SEDDON, Danielle Santos do Nascimento. Vulnerabilidade social no Espírito Santo: conceito e mensuração. 2014. 104 f. Dissertação (Mestrado em Economia) - Universidade Federal do Espírito Santo, Vitória, ES, 2014.

STOCO, Sergio; ALMEIDA, Luana Costa. Escolas municipais de Campinas e vulnerabilidade sociodemográfica: primeiras aproximações. Revista Brasileira de Educação. São Paulo, v. 16, n. 48, p. 663-694, set./dez. 2011.

TORRES, Haroldo da Gama et al. Perfis do professorado da rede pública de São Paulo: a interação entre espaço, regras institucionais e escolhas individuais no resultado de uma política pública. Dados - Revista de Ciências Sociais. Rio de Janeiro, v. 53, n. 1, p. 125158, jun. 2010.

\section{Notas}

' O texto é um recorte de uma pesquisa maior, que visou obtenção do título de Mestre em Educação, que investigou a implementação do programa Pacto Nacional para Alfabetização na Idade Certa (PNAIC), na rede de ensino do município de São Paulo, em um contexto de vulnerabilidade social e contou com apoio da FAPESP [processo n. 2018/11257-6] (GIUSTO, 2018). 